\title{
TEORÍAS ABSOLUTAS DE LA PENA
}

\author{
CUStodio Vegas, Gianfranco ${ }^{99}$
}

SUMARIO: 1. Introducción - 2. Teorías Absolutas de la pena - 3. Fundamentación Religiosa - 4. Fundamentación Moral - 5. Fundamentación Jurídica - 6. Críticas a las Teorías Absolutas de la pena- 7. Jurisprudencia relativa a las Teorías Absolutas de la Pena

\section{Introducción}

La fundamentación de la pena ha sido uno de los temas más discutidos en materia de Derecho Penal, por filósofos y juristas en el transcurso de la historia. La importancia de determinar su fundamento radica en la necesidad de justificar su uso, para evitar que parezca un acto arbitrario por parte del estado en uso del Ius Puniendi y evitar así una crisis que pueda llevar, en última instancia, a la disolución del estado por una desaprobación general de sus habitantes o a una suerte de "Régimen del Terror" como el ocurrido entre 1793 - 1794 en Francia.

En la actualidad, bajo el sistema liberal y un modo de gobierno de ideología demócrata social, se fundamenta la pena através de la llamada teoría Mixta o Unitaria, que sostiene que "la pena debe reprimir tomando en cuenta la culpabilidad y la proporcionalidad con respecto al hecho delictivo y a la vez prevenir la comisión de nuevos delitos ${ }^{100}$ de este modo se logra un balance entre las dos teorías preponderantes en materia de doctrina penal, las Teorías Absolutas y las Teorías Relativas.

En lo que respecta a este trabajo el ámbito de investigación se encontrara limitado a las teorías absolutas de la pena, llamadas también teoría retributivas. Se analizara su

99 Alumno de la Facultad de Derecho y Ciencias políticas de la Universidad Ricardo Palma. Miembro del Centro de Investigación.

${ }^{100}$ Villavicencio Terreros, Felipe. Derecho Penal Parte General 
fundamento general, así como también sus tres fundamentaciones básicas: La Religiosa por Santo Tomas de Aquino y San Agustín; la Moral encabezada por Immanuel Kant; y por último la justificación la Jurídica por Hegel.

Así también veremos las críticas que ha recibido esta teoría a lo largo del tiempo.

Por último veremos los fallos emitidos por el Tribunal Constitucional con respecto a la aplicación de estas teorías para justificar la pena en el ámbito del derecho penal peruano.

\section{Teorías Absolutas de la Pena}

Antes de comenzar con la fundamentación general de estas teorías es pertinente dar un acercamiento a la realidad histórica en la que surgen las ideas fundantes de esta forma de ver la pena.

La idea de la pena considerada como un mal que retribuye un mal encaja de manera precisa en una sociedad bajo el imperio de un régimen absolutista, esta afirmación se da por la razón de que en estos estados se da la unión y dependencia de tres aspectos que, actualmente, pueden separarse con facilidad o al menos se pueden tratar de manera independiente sin mucha dificultad, los cuales son Soberano, Religión y Derecho. Una característica principal de este tipo de gobierno es la dependencia del soberano (el monarca) ante la religión, ya que no se debe olvidar que la idea de soberanía no es la que nos presenta Sieyés o la que plantea luego Locke o Hobbes, sino que es una concepción de soberanía que parte del denominado "mandato divino" el cual, en líneas generales, señala que la soberanía del monarca proviene de origen divino, lo que implica una rendición de cuenta solo a este ente superior, dejando de lado el tener que explicar o justificar sus acciones a la población. Dentro de este esquema la religión juega un papel legitimador de la soberanía ya que, al ser la iglesia una institución con una supuesta cercanía a lo divino era la que, al final de cuentas, podía exaltar y apoyar al rey o también podían, en caso vieran necesario, quitarle el apoyo y con este su legitimidad ante el pueblo.

Así también, no solo la religión y el poder político estaban ligados, sino también el derecho, y dentro de este la capacidad del estado para imponer sanciones (Ius Puniendi) la cual se entendía que también provenía de origen divino, y era entonces considerada la voluntad del gobernador como la voluntad ultima de Dios al ser este, como se explico líneas más arriba, un nexo entre lo divino y lo terrenal.

Bajo estos parámetros se considera entonces a la pena como un "mal que sirve para retribuir la culpabilidad del agente del hecho delictivo"101, pero a su vez es considerada como una forma de expiación del pecado cometido (delito), y este último supuesto va de

${ }^{101}$ Vidaurri ArechiagA, Manuel, Teorías de la Pena 
la mano con la idea de que al ser la voluntad del soberano la voluntad de Dios, revelarse ante el soberano es, en última instancia, revelarse ante el mismo Dios.

Posteriormente a la caída del estado monárquico luego de las revoluciones sociales, sobre todo luego de la Revolución Francesa siendo esta la expresión más fuerte de la voluntad general del pueblo, la teoría de la retribución cambia y se pone en concordancia con la fundamentación estatal del Contrato Social en donde el que comete un delito es considerado como un traidor, ya que va en contra de la voluntad general de la sociedad y en última instancia en contra de la razón de ser del propio estado ${ }^{102}$, y ahora el fin de la pena es aun más duro, ya que lo que busca es la consecución de la Justicia. Ahora el fundamento de la sanción se encuentra en el Libre Albedrio, comprendido como la capacidad del hombre para distinguir lo bueno y lo malo y, de a cuerdo a eso, actuar destacando entonces que luego de haber hecho el test de lo correcto e incorrecto el delincuente a decidido actuar de manera contraria a la voluntad general y por esa razón es sancionable. Este mismo argumento puede, en cierta medida, justificar el uso del principio de Talión para la búsqueda de la justicia, en cuanto si ha sido la voluntad del infractor la de violar el orden social no hay medida más equitativa y proporcional que aplicar el fundamento de "Ojo por ojo, diente por diente" expresándolo como la voluntad del estado en respuesta de la decisión del delincuente de violar el orden social.

La idea de retribución descansa sobre tres presupuestos esenciales: ${ }^{103}$ Primero, la potestad estatal para castigar al responsable mediante la pena, Segundo, la necesaria existencia de una culpabilidad que pueda ser medida según la gravedad del injusto cometido, siendo entonces la culpabilidad el elemento de referencia principal. Tercero la necesidad de armonizar el grado de la culpabilidad y la gravedad de la pena.

Dentro de los defensores de estas teorías podemos señalar a dos de los más grandes pensadores en lo que a filosofía del derecho se refiere, estos son Hegel y Kant ambos altos pensadores del idealismo alemán, así también dentro de los defensores de estas teorías se encuentran Santo Tomas de Aquino y San Agustín, con la excepción de que su concepto de pena es una suerte de expiación.

\section{Fundamentación Religiosa}

Como se menciono en líneas anteriores esta fundamentación recae en manos de Tomas de Aquino y San Agustín. En lo relevante a este punto es necesario hacer una reseña histórica, breve, ya que de ella es que surge todo el modo de pensar que fundamenta esta argumentación en defensa de la retribución Divina como es llamada en este fundamento.

\footnotetext{
102 SIEYÉS. ¿Qué es el Estado Llano?

103 JESCHECK/WEIGEND, 2002, p.72
} 
Como ya se menciono en el "antiguo régimen" el modo de gobierno era del tipo Teocrático, lo que implica un gran sometimiento a las imposiciones que, en teoría, provenían de los dioses, bajo este supuesto es que nace la idea de la retribución divina, en cuanto las leyes eran enviadas por los dioses lo que les da un carácter sagrado e inviolable. La primera expresión que se da sobre una ley emanada directamente de los dioses se da con el "Código Hammurabi” otorgado al Rey Hammurabi de Babilonia y que es utilizado para regular la voluntad de los jueces y pretender tener leyes para todas las situaciones que se presenten y evitar que ante cada situación el juez actuara a su conveniencia.

Esta argumentación relaciona análogamente al delito con el pecado, logrando así un cambio en el sentido de la retribución, volviéndola entonces en una suerte de expiación del pecado. Bajo el marco religioso entonces la pena viene a ser "La expurgación del mal a través del dolor otorgo sentido a la pena que de esta manera redimía al hombre”104

\section{Fundamentación Moral}

El principal exponente de esta fundamentación es el filosofo alemán Immanuel Kant, su argumentación comienza con el supuesto de que la pena ha de ser considerado un Imperativo categórico por lo tanto ha de ser considerada como un mandato que "representase una acción por sí misma, sin referencia a ningún otro fin. Como objetivamente necesaria” ${ }^{\text {105 }}$.

Kant es considerado como el fundador teórico del Estado de Derecho y su estructura jurídica racional. El considera al estado como la racionalización formal del orden jurídico, por lo tanto no proviene de la naturaleza ni de la voluntad libre ${ }^{106}$.

Para Kant un principio fundamental es el de la libertad, bajo este mismo derecho erige la figura del acto delictivo como un mal uso de esa libertad, lo que vendría a ser igual a haber hecho mal uso de su libre albedrio yendo en contra de la voluntad general lo que lo vuelve "acreedor" de un mal (como diría una posición religiosa del tema) a un mal, que es en este caso la pena. Kant llama al derecho penal Derecho a Castigar y lo interpreta de la siguiente manera :”

La pena jurídica, poena forensis, no puede nunca aplicarse como un simple medio de procurar otro bien, ni aun en beneficio del culpable o de la sociedad; sino que debe serlo contra el culpable por la sola razón de que ha delinquido; porque jamás un hombre

${ }^{104}$ ORTIZ ORTIZ, 1993.p. 112
${ }^{105}$ KANT, Fundamentación Metafísica..., p, 61 y ss.

106 CABRERA, Sandra. Teorías Absolutas de la pena, Extraída de [http://www.urbeetius.org/newsletters/03/s_cabrera.pdf] con fecha 4 de Diciembre del 2010 
pudo ser tomado por instrumento de los designios de otro ni ser contado en el numero de las cosas como objeto del Derecho Real”. Según Kant entonces, el hombre no puede ser considerado bajo ninguna circunstancia como un instrumento para lograr un bien común o una mejor sociedad, así tampoco debe ser considerada la tesis de la prevención especial, en cuanto no puede ser aplicada la pena para prevenir futuras acciones delictivas del mismo sujeto, lo que implicaría al final una corrección, ergo, un bien para el propio individuo, algo que Kant también proscribe, sino que hay que castigar al sujeto por el solo hecho de haber delinquido, por haber transgredido la ley racional.

\section{Fundamentación Jurídica}

Antes de exponer la argumentación y defensa de Hegel sobre las teorías absolutas, cabe explicar de manera breve su postura lógica, con la cual explicara posteriormente la evolución del acto punitivo.

Para comprender la filosofía hegeliana se pueden aplicar tres etapas o momentos en la aplicación de su filosofía: la Tesis, la Antítesis y la Síntesis ${ }^{107}$

La tesis es entendida como el momento inicial y corresponde al estar en sí, es también la revelación del momento abstracto que será accesible al entendimiento.

La antítesis comprende entonces el momento en el que el estar en sí, sale de sí mismo y se niega, logrando así objetivar el momento, llevando en si a un plano “exterior” a sí mismo.

Y por último se llega a la síntesis, que es entendida como una negación de la negación o una reconciliación con el momento inicial.

Bajo estos tres conceptos Hegel ha analizado a la pena concluyendo lo siguiente: El delito implica la negación de la voluntad general, aplicando una voluntad especial (síntesis), la pena implica la negación de la voluntad general (antítesis), y posteriormente se regresara al estado primero donde prima la voluntad general (síntesis).

Así mismo Hegel considera que la pena no debe de aspirar a fines posteriores de carácter útil a la sociedad o al sujeto, al igual que Kant la pena es aplicable al sujeto por haber delinquido, por lo tanto la pena es retributiva por que según la intensidad de la negación del derecho así también será la intensidad de la pena aplicable o la nueva negación.

${ }^{107}$ Este modo de expresar los pasos para la aplicación de la filosofía hegeliana no fueron acuñados por Hegel en ningún momento, esta forma de expresarlo, llamada por algunos "trilogía Dialéctica” es usada anteriormente por Fichte para explicar las relaciones entre el individuo y el mundo. Por lo tanto el uso de estos términos es únicamente para la enseñanza de manera didáctica de la filosofía de Hegel y es usado en este trabajo con la misma finalidad, para simplificar para decirlo de algún modo, el pensamiento complejo de Hegel al defender esta teoría. 
Entre la teoría de Kant y Hegel se encuentra cierta similitud en lo referente a la no instrumentalización del hombre, así podemos encontrar también en palabras de Hegel: "Solo mediante la pena se le trata al delincuente como un ser racional y libre; únicamente así se le honra dándole no ya algo justo en sí, sino su Derecho: a diferencia del inadmisible modo de proceder de quien propugna principios preventivos, conforme a los cuales se amenaza al hombre como cuando se le muestra un palo a un perro, y el hombre por su honor y su libertad, no debe ser tratado como un perro."108

Para Hegel la aplicación de la pena es el restablecimiento del sistema jurídico a partir de la negación del delito, y la aplicación del principio de talión es el medio por el cual se determina la equivalencia entre el delito y la pena.

Como podemos ver ambas teorías, la Hegeliana y la Kantiana, poseen puntos de vista concordantes, como por ejemplo: La retribución al autor del delito con una pena proporcional al mal ocasionado; en ningún caso la pena debe perseguir fines que escapen a "castigar" al individuo que causo el daño.

Se destaca que ambas teorías se han visto motivadas también por el contexto histórico, considerando que han surgido en una época en donde la libertad personal del hombre se encontraba en la cúspide de todo ordenamiento y base del contrato social.

\section{Críticas a las Teorías Retributivas ${ }^{109}$}

Posterior a la fundamentación de estas teorías surgieron criticas en tres aspectos importantes, y en cierta forma fundamentales en lo que ha sustento se refiere. Los temas a los que iban dirigidas las críticas eran: Fundamento y límite del "Ius Puniendi", Imposibilidad de verificar el libre albedrío y lo que se llamo una La racionalización de la venganza.

En lo referente al Fundamento y límite del "Ius Puniendi":

- Deja en manos del estado en momento de aplicación de la pena, puesto que las teorías solo mencionan el por qué de esta.

- No fija límites en la capacidad estatal de aplicación del Ius Puniendi, lo que en la comprensión actual se interpreta como un abuso del poder por parte del estado.

- Concluye, en última instancia, la necesidad de la pena, y a sí mismo el hecho de castigar al delincuente en todos los casos aunque no sea necesaria en algunos.

En lo referente a la Imposibilidad verificación del Libre Albedrio

${ }^{108}$ De Toledo y UBIETO, Emilio Octavio, Sobre el Sentido del Derecho Penal, p.303

109 Investigación llevada a cabo por el congreso de la república, extraída de [http://www.congreso.gob.pe/historico/cip/materiales/extorsion/Teorias_pena_investigacion.pdf] con fecha 3 de diciembre del 2010 
- Se sostiene que el libre albedrio es el que determina la culpabilidad del sujeto y que teniendo el libre albedrio como base es que se sustenta el poder del estado para castigar, lo que resulta irracional considerando la imposibilidad de demostrar empíricamente la existencia de este albedrio.

El pago del mal con el mal. La venganza racionalizada.

- La idea de mal por mal responde a una reacción propia de venganza del ser humano, la argumentación de que el estado realice esta venganza a través de la pena es solo justificable en cuanto el estado pena antes de que se realice le venganza por la propia mano de los afectados.

- La pena como venganza o retribución en realidad no repara el mal que se realizo, el principio de talio no devuelve el ojo del afectado al quitarle el ojo al agresor.

Muy aparte de las críticas que se hayan planteado el Derecho Penal contemporáneo no ha dejado de lado los postulados que se derivan de estas teorías, muestra de ello son las llamadas teorías mixtas o unitarias de la pena, que buscan la prevención de futuros actos delictivos, pero a su vez tienen un arraigado sentimiento de justicia dentro de las resoluciones dictadas.

\section{Jurisprudencia Relativa a las Teorías Absolutas de la Pena}

El Perú dentro de su ideología social demócrata acepta las teorías Mixtas o Unitarias como sustento de la pena y del poder para castigar del estado, así lo demuestra en la sentencia del Tribunal Constitucional 0019-2005-IP/TC en donde proscribe, en su fundamento 30, el uso de las teorías retributivas "puras" para la fundamentación de la pena:

Son distintas las teorías de los fines de la pena desarrolladas en la doctrina. Una es la teoría de la retribución absoluta, cuyos exponentes son Kant y Hegel. Según ella, la pena no cumple ninguna función social, pues es una institución independiente de su esfera social; es decir, agota toda virtualidad en la generación de un mal al delincuente, de modo tal que el Estado, en representación de la sociedad, toma venganza por la afectación de algún bien jurídico relevante, aplicando un mal de similar gravedad a la relevancia del bien en el ordenamiento jurídico. Se trata de la concreción punitiva del antiguo principio del Talión: “ojo por ojo, diente por diente”.

Esta teoría no sólo carece de todo sustento científico, sino que es la negación absoluta del principio-derecho a la dignidad humana, reconocido en el artículo $1^{\circ}$ de nuestra Constitución Política, conforme al cual: 
"La defensa de la persona humana y el respeto por su dignidad son el fin supremo de la sociedad y el Estado."

Bajo esta sentencia entonces el TC determina que el empleo de fundamentaciones retributivas atenta contra la dignidad del hombre protegida en el art. $1^{\circ}$ de la Constitución Política, en cuanto no se puede aplicar penas que atenten, por ejemplo contra el honor o la integridad física o psicológica de la persona.

En opinión personal comparto la postura del TC en lo referente al tipo de pena a aplicar, en lo que nos referimos en el párrafo anterior de la prohibición de tratos crueles o inhumanos en la aplicación de una pena. Sin embargo difiero en parte a lo que dignidad humana se refiere, sin pretender abarcar todo lo que esta palabra implica en el derecho solo procuro poner en la bandeja el hecho de que si bien es cierto una pena con una naturaleza meramente física es, por razones obvias, inaplicable, la justificación de las teorías retributivas también procuraban salvaguardar la dignidad de las personas, citando a Kant " la persona no puede ser reducida a un instrumento para la consecución de un fin o bienestar, ya sea del estado o del mismo sujeto”, tomando en cuenta esa fundamentación de Kant considero que no es una "negación absoluta del derecho a la dignidad humana" sino que en la teoría subyace también una posición en defensa a la dignidad humana, y la postulación del TC, en lo personal, me parece muy estricta, o muy poco inclusiva por así llamarlo.

\section{TEORÍAS ABSOLUTAS DE LA PENA}

\section{BIBLIOGRAFÍA}

Villavicencio Terreros, Felipe. Derecho Penal Parte General; Vidaurri Arechiaga, Manuel, Teorías de la Pena; Jescheck/WeIgend, 2002, p.72; SieYÉs. ¿Qué es el Estado Llano?; OrTiz OrTIZ, 1993; CABrerA, Sandra. Teorías Absolutas de la pena; De Toledo y Ubieto, Emilio Octavio, Sobre el Sentido del Derecho Penal 